\title{
Tick control by small-scale cattle farmers in the central Eastern Cape Province, South Africa
}

\author{
P J Masika ${ }^{\mathrm{a}}, \mathrm{A}$ Sonandi ${ }^{\mathrm{a}}$ and $\mathrm{W}$ van Averbeke $^{\mathrm{a}}$
}

\begin{abstract}
A survey conducted in 5 magisterial districts involving rapid rural appraisal and a questionnaire showed participation in state-managed and funded dipping programmes by cattle owners in communal areas of the central Eastern Cape to be nearly complete, with $98 \%$ of livestock owners interviewed participating in all dipping events. Disease control was the main reason for participation, but farmers perceive dipping to have a much broader disease-preventing activity than is really the case. Other reasons for participation in dipping programmes were to prevent ticks from sucking blood, provide animals with a clean appearance, and prevent damage to teats of cows. Many livestock owners complement dipping with other tick control measures, including old motor oil, household disinfectant, pour-on acaricide and manual removal of ticks. Recently local farming communities were given the responsibility of buying dipping acaricide. This has presented them with the challenge of developing farmer-managed, cost-effective tick control programmes. At present, this process is constrained by lack of information and farmer training.
\end{abstract}

Key words: cattle, central Eastern Cape Province, communal farmers, dipping, tick control.

Masika P J, Sonandi A, Van Averbeke W Tick control by small-scale cattle farmers in the central Eastern Cape Province, South Africa. Journal of the South African Veterinary Association (1997) 68(2): 45-48 (En.). Farming Systems Research and Extension Unit, ARDRI, University of Fort Hare, Private Bag X1314, Alice, 5700 South Africa.

\section{INTRODUCTION}

Ticks, and diseases they transmit, are present throughout the world, but they are most prevalent and numerous and exert their greatest impact in tropical and subtropical regions ${ }^{4}$. Large parts of South Africa are subtropical, and here animal husbandry is also severely constrained by tick-borne diseases. Animal farming in the communal areas of the Eastern Cape Province (Fig. 1) is concerned mainly with production of cattle, goats and sheep. Locally, ticks and tick-borne diseases are considered a major problem in cattle, but less so in goats and sheep. The major tickborne diseases affecting cattle in the Eastern Cape are gallsickness, redwater and heartwater ${ }^{12}$.

Use of acaricides in the control of ticks has improved the viability of cattle farming in the tick-infested areas. Cattle dipping, whereby the animals are immersed in a plunge dip filled with an acaricide solution, is one of the ways in which ticks, and the parasites they transmit, are controlled. During the early

${ }^{\mathrm{a}}$ Farming Systems Research and Extension Unit, ARDRI, University of Fort Hare, Private Bag X1314, Alice, 5700 South Africa.

Received: August 1996. Accepted: April 1997. 20th century, the Veterinary Service of the Department of Agriculture of South Africa initiated a tick control programme after the introduction of the deadly disease east coast fever from East Africa ${ }^{10}$. Several measures were instituted by the department, including dipping, which proved to be the most practical and effective measure of all. As a result it was widely adopted by farmers and later made compulsory by the state ${ }^{10}$. After the eradication of east coast fever (considered to have been achieved by 1960), compulsory dipping was abolished on white-owned farms. In the homelands, however, compulsory dipping continued to be enforced, because animal health authorities viewed the cattle in communal areas as a source of infections, with tick-borne diseases being of major concern. By continuing the dipping service, the department hoped to reduce and, if possible, eradicate the tick population in these areas. Animals were marked after each dipping session, and unmarked animals were impounded. During the 1970s, management of the dipping service was handed over to the former homeland administrations. In Ciskei, livestock owners paid a fee for each animal dipped $^{13}$, whereas in Transkei fees were collected in the form of a grazing levy, payable annually. The dipping service was maintained by the new administrations, but enforcement of the dipping programme was gradually relaxed, to be removed completely after independence of these homelands in 1975 (Transkei) and 1981 (Ciskei). When Ciskei and Transkei were reincorporated into South Africa in 1994, the Provincial Department of Agriculture accepted responsibility for the dipping service, supplying both personnel and chemicals. In April 1996 (Daily Despatch, 30 May 1996), budgetary constraints caused the department to suspend the supply of chemicals, limiting its contribution to the programme to supplying personnel only. The responsibility of purchasing dipping chemicals was left to the farming communities.

The objectives of the present study were to assess present levels of participation by livestock owners in the communal areas in dipping programmes, the reasons for their participation, and to document the tick control practices that are used by the target group in addition to dipping. This knowledge is required to assist communal farmers in formulating and managing cost-effective tick control programmes.

\section{MATERIALS AND METHODS}

The study was conducted in 5 districts in the central part of the Eastern Cape Province, namely Victoria East, Keiskammahoek, Middledrift, Zwelitsha and Mdantsane, all of which formed part of the former Ciskei. The target group consisted of livestock owners who produce cattle on communally managed rangeland.

The investigation was conducted in 2 phases. In a preliminary investigation from April to June 1995, matrix ranking, diagramming and group interviews, which form part of the rapid rural appraisal (RRA) family of techniques ${ }^{5}$, were used to elicit information from a total of 138 participants. Most appraisal meetings were organised to coincide with livestock inspection or dipping days. The others occurred at formal or informal farmers' meetings.

The 2nd phase of the study constituted 


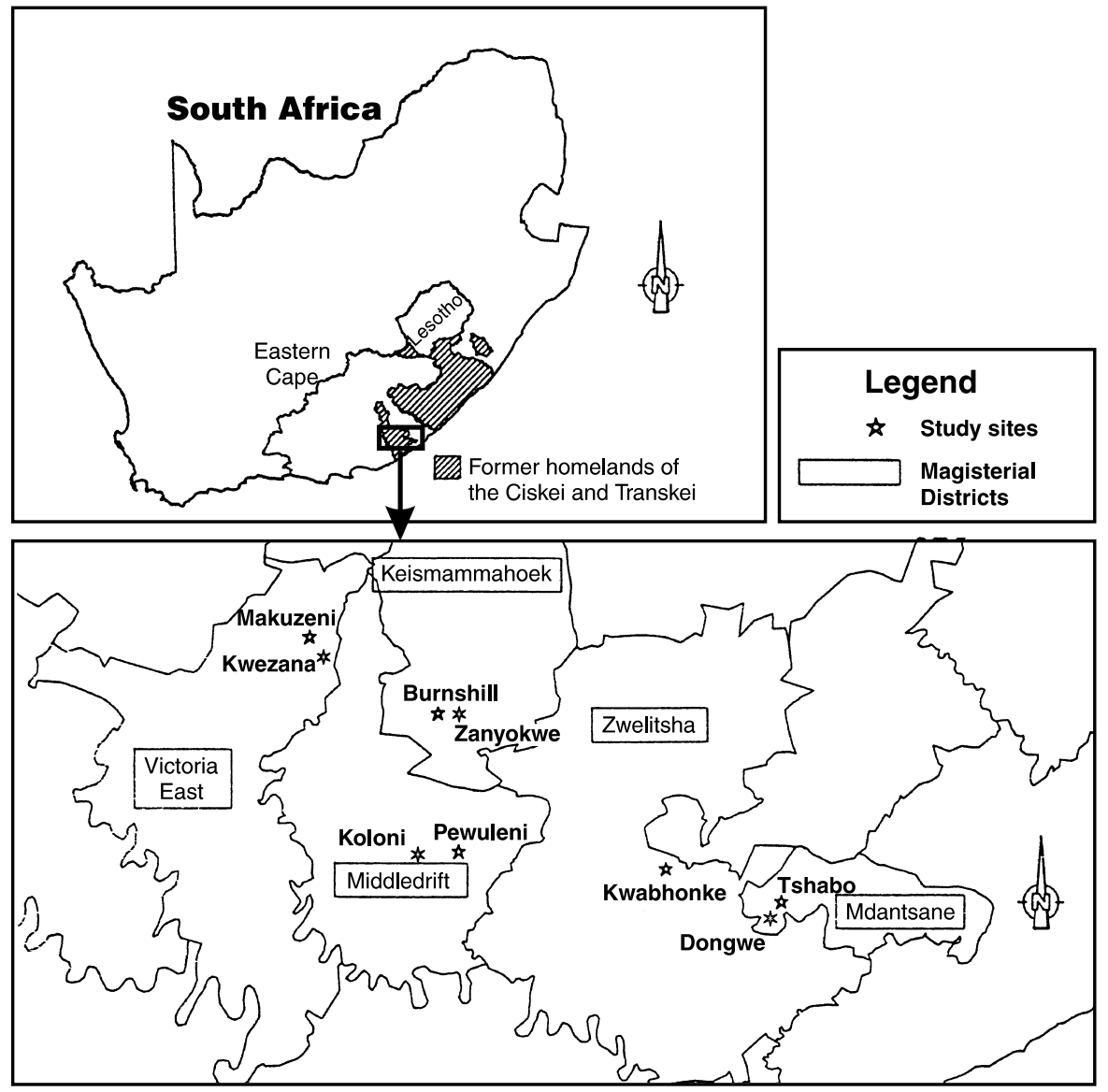

Fig. 1: Map of South Africa (top) showing the location of the Eastern Cape Province and the former homelands of Transkei and Ciskei, and the districts and sites where the study was conducted (bottom).

a formal questionnaire survey. This survey enabled quantitative data to be obtained, free of bias introduced by group dynamics, which may affect similar data obtained using RRA techniques ${ }^{5}$. Design and content of the questionnaire were guided by the analysis of responses obtained in RRA meetings. The questionnaire was pre-tested for content validity and reliability, whereafter it was given to 60 respondents. None of the respondents to the questionnaire had previously participated in the RRA meetings. Responses to the questionnaire were analysed using the PC programme NWA Statpak, version 3.2 (North West 2 Analytical, Portland, Oregon). The questionnaire survey was conducted at 5 sites consisting of 1 or 2 locations. The sites were Makuzeni and Kwezana (Victoria East district), Koloni (Middledrift district), Zanyokwe and Burnshill (Keiskammahoek district), Kwabhonke (Zwelitsha district) and Tshabo and Dongwe (Mdantsane district). Potential respondents were identified as being owners of holding pens with high and densely woven walls. Experience had shown that

such holding pens were used almost exclusively for cattle. The owners of these holding pens were visited singly and asked if they were willing to respond to the questionnaire. In each of the 5 target areas this procedure was repeated until 12 responses had been obtained. The survey was conducted during the period October to November 1995, well before the intention of the Provincial Government to withdraw from the supply of dipping chemicals became known.

\section{RESULTS AND DISCUSSION}

\section{Level of participation in dipping programmes}

Participation by respondents in the dipping programme funded and managed by the Eastern Cape provincial government was nearly total, with $98 \%$ of respondents indicating consistent participation in every dipping event. The state ceasing to enforce participation appears to have had little effect on the level of participation by livestock owners in the dipping programme, which was high at the time of the survey, suggesting that livestock owners perceive dipping to be beneficial. Dipping, therefore, can be considered as a very successful government intervention in the local livestock production system.

\section{Reasons for participating in the dipping programme}

Reasons for participation are shown in Fig. 2. Control of diseases was the main reason, but not all the diseases farmers perceive to be prevented by dipping are actually transmitted by ticks. Examples of such diseases are blackquarter, three-day stiff sickness (bovine ephemeral fever) and anthrax. This suggests that farmers perceive dipping to be a disease control measure with an activity much broader than is really the case. Killing ticks and preventing them from sucking blood was the secondmost important reason. The estimated mean damage caused by each adult female Rhipicephalus appendiculatus (brown ear-tick) counted on an animal in Africa has been estimated to be $4.4 \pm 0.8 \mathrm{~g}$ loss in live mass gain ${ }^{8}$ and approximately $10 \mathrm{~g}$ for Amblyomma hebraeum (bont tick) ${ }^{9}$. It appears that many farmers are conscious of the negative effect of tick activity on their livestock performance. Specific mention of avoiding damage to teats, which ranked high amongst the reasons for dipping, emphasises the importance attached to milk as a major benefit derived from keeping cattle, reported on by several authors ${ }^{6,7}$.

\section{Tick control methods other than dipping}

Many cattle owners were found to complement dipping with other tick control measures, the range of which is shown in Fig. 3. The use of additional tick control measures was found to be adopted by $39 \%$ of respondents for 2 main reasons, namely the perception that ticks had developed resistance to the acaricide supplied by the state and the desire of free of ticks. In the communal areas of the central Eastern Cape Province, acaricide resistance by ticks has not been investigated, but development of such resistance has been reported by the commercial farming sector in the Province ${ }^{12}$. Generally, Xhosa livestock owners derive extreme pride from a clean and well-cared for herd of cattle, and resort to means other than dipping to maintain the desired appearance of their animals. The tedious practice of reducing tick numbers on cattle by cutting them off using razor blades or scissors or by pulling them off the animals by hand, practised by approximately $10 \%$ of the livestock many farmers to keep their animals totally 
Reasons for dipping

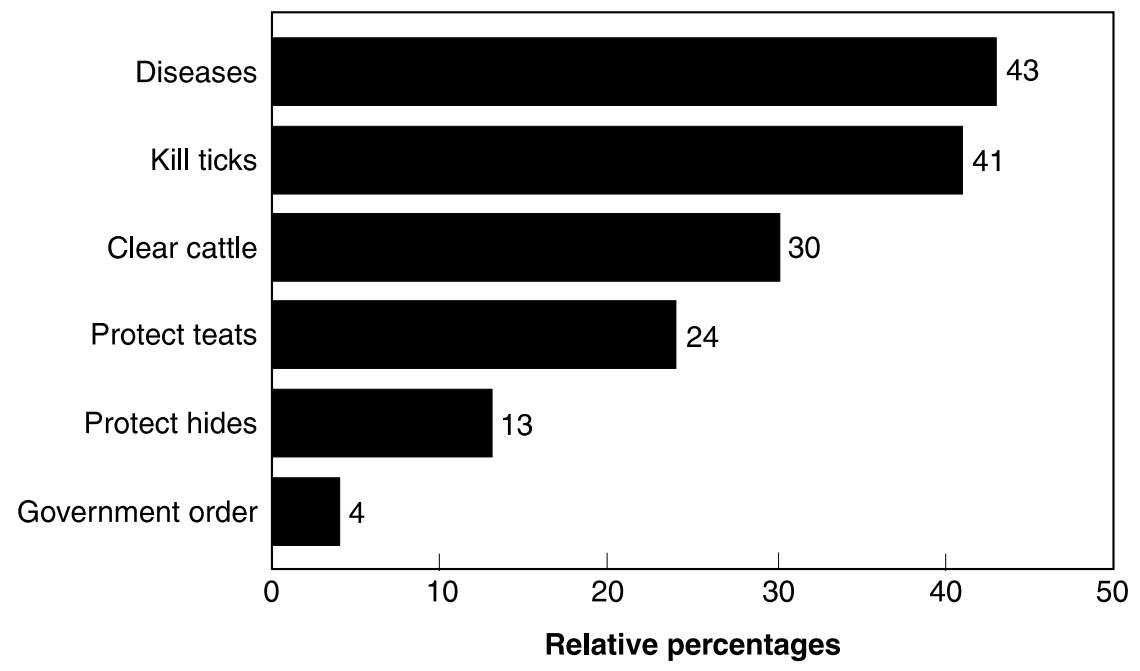

Fig. 2: Reasons why farmers in the communal areas of the central Eastern Cape Province participate in the state-managed dipping programme.

\section{Method of tick control}

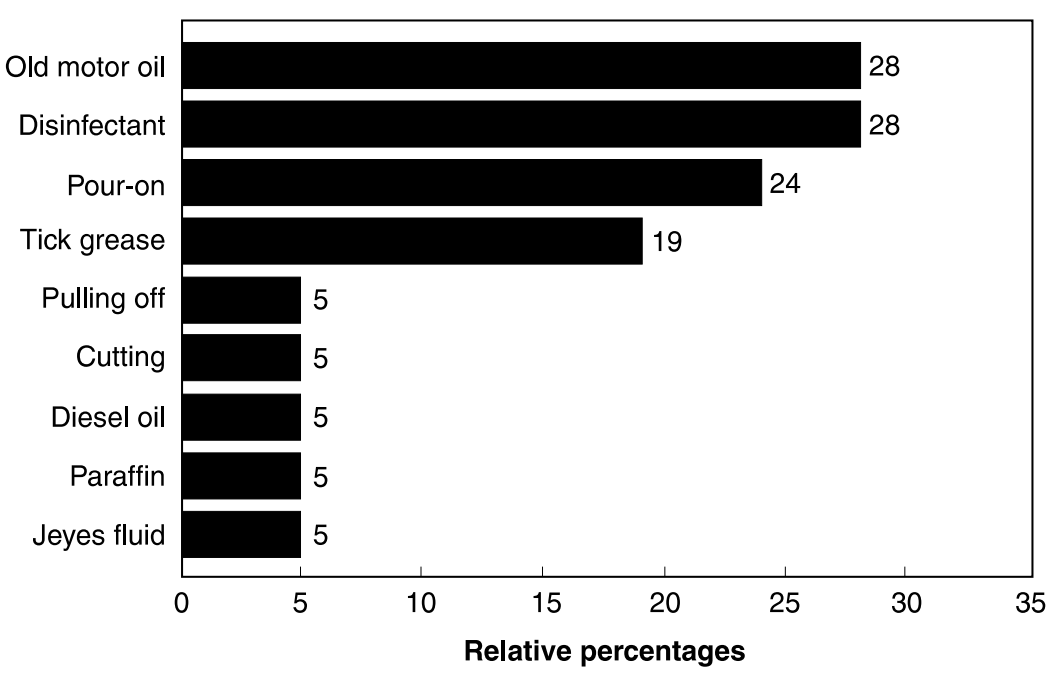

Fig. 3: Complementary tick control measures used by farmers in the communal areas of the central Eastern Cape Province.

owners, is proof of the effort farmers are prepared to make to keep their animals clean. However, keeping animals completely free of ticks is no longer considered good practice, as it is known to result in enzootic instability ${ }^{1,2}$, brought about by injudicious control of ticks preventing animals from coming into contact with infected ticks ${ }^{1}$.

Use of old motor oil and a household disinfectant, (Madubula, Newden) were the most common amongst the complementary tick control methods. Both substances are cheap and readily available, which may explain why farmers lated ( $p=0.05)$ with the number of animals they reported to have lost over the past 5 years. It could be that the use of pour-on products was initiated as a result of a spate of high mortalities. It is also possible that intensive use of pour-on products may have resulted in a situation of enzootic instability through excessive tick control. Users of pour-on products apply the chemical weekly or biweekly. Of the farmers using complementary control measures, $14 \%$ mix pour-on products with other substances such as old motor oil, diesel and paraffin. Mixing pour-on products with other substances effectively reduces the dose of active ingredient applied to the animal, but sublethal doses of flumethrin have been reported to inhibit oviposition or to render tick eggs non-viable, which can provide a valuable adjunct to integrated tick management ${ }^{11}$. Mixing may also deactivate the acaricidal effect of the pour-on product, thus rendering it useless.

\section{The future of tick control in communal areas}

Recent information indicates that Sanga and Zebu cattle, which have a high degree of tick and tick-borne disease resistance ${ }^{10}$, require minimal tick control, ranging from total absence of control in dry areas, to strategic control during the wet season when reared in humid areas. European breeds of Bos taurus, which lack the genetic tick resistance of their African counterparts, require intensive tick control for the greater part of the year in all but the dry climatic areas. In these cattle breeds intensive tick control can be eliminated only when tick-borne diseases are controlled through an immunisation programme ${ }^{10}$.

Integrated tick control, based on host resistance combined with strategic acaricidal treatments, appears therefore to be the only viable short- to medium-term approach to the sustainable control of ticks and associated diseases in these areas. Immunisation has been proposed as a viable option ${ }^{12}$, but at present the infrastructure required to support an effective immunisation programme in communal areas is not in place.

In the long term, farmers should be encouraged to keep indigenous breeds with proven tick resistance and high levels of immunity to tick-borne diseases $^{12}$. This would require the Department of Agriculture to embark on a major information campaign to inform smallscale farmers of the advantages of indigenous stock. Advantage should be taken of age-related resistance of livestock, which 
is known to prevail in young calves ${ }^{2}$, whereby one could stimulate immunity to the different tick-borne diseases either naturally or artificially. In rural areas, however, calves are kept at the homestead to prevent them from suckling their dam or getting lost and to protect them from predators. As a result, they are not exposed to ticks, and immunity to tickborne diseases is not developed. Exploiting age-related resistance would thus require a change in the husbandry practices of local farmers.

\section{CONCLUSION}

In the Eastern Cape Province, dipping is one of the major interventions by the state in communal livestock production systems. The present study shows that the practice enjoys voluntary support by the majority of local cattle owners, who know that dipping can control ticks and certain diseases, but lack knowledge of the type of diseases concerned. Farmers were found to use tick control measures other than dipping, but the efficacy of many of these measures is not known and they may in some instances be dangerous. There is a need for appropriate information to be provided to livestock owners, explaining the relationship between ticks and tick-borne diseases to improve their understanding of the causes of these diseases. Discontinuation of tick control by the government is expected to cause a dramatic increase in the number of tickborne disease-related livestock mortalities, unless owners start purchasing acaricide themselves. This would require farmers to be provided with information and training on selection, dosage and correct use of the different acaricides available on the market. A change in genetic composition of the herd aimed at increasing tick resistance and immunity and exploitation of age-related tick-borne disease resistance are possible ways in which to reduce the need for tick control over time. This will require a change in the perceptions and practices of farmers. Dipping days and group discussions are suitable occasions at which to share information and provide training to livestock owners.

\section{ACKNOWLEDGEMENTS}

The authors acknowledge the financial contribution of the National and Eastern Cape Departments of Agriculture and Land Affairs that made this work possible, and the assistance of Mr Laurent Chauvet of the Department of Surveying at the University of Fort Hare, with preparation of the maps.

\section{REFERENCES}

1. Bezuidenhout J D 1985 The epizootiology and control of heartwater and other tickborne diseases of cattle in South Africa. Onderstepoort Journal of Veterinary Research 52: 211-214

2. Bezuidenhout J D, Bigalke R D 1987 The control of heartwater by means of tick control. Onderstepoort Journal of Veterinary Research 54: 525-528

3. Blood D C, Radostits O M, Henderson J A 1983 Veterinary Medicine (6th edn). Baillière Tindall, London

4. Bram R A 1983 Tick-borne livestock diseases and their vectors: the global problem. In
FAO Ticks and tick-borne diseases, FAO animal production and health paper No. 36. FAO, Rome: 7-11

5. Chambers R 1992 Rural appraisal: rapid, relaxed and participatory. Institute of Development Studies, Discussion paper 311

6. Duvel G H, Afful D B 1994 Human constraints in stock reduction and communal land management in a subsistence farming situation in South Africa. Research Report, South African Institute for Agricultural Extension. University of Pretoria, 7-14

7. Masika P J, Sonandi A, Van Averbeke W, Goqwana M 1996 Livestock production systems. In ARDRI's Farming Systems Research Programme, Preliminary Report. ARDRI, University of Fort Hare

8. Norval R A I, Sutherst R W, Kurki J, Gibson J D, Kerr J D 1988 The effect of the brown ear-tick Rhipicephalus appendiculatus on the growth of Sanga and European breed cattle. Veterinary Parasitology 30: 149-164

9. Norval R A I, Sutherst R W, Jørgenson O, Gibson J D, Kerr J D 1988 The effect of the bont tick (Amblyomma hebraeum) on the growth of Africander steers. Veterinary Parasitology 33: 329-341

10. Norval R A I 1994 Vectors: ticks. In Coetzer J A W, Thomson G R, Tustin R C (eds) Infectious diseases of livestock with special reference to Southern Africa Vol. 1. Oxford University Press, Cape Town: 3-24

11. Schröder J 1987 Chemical control of the heartwater vectors. Onderstepoort Journal of Veterinary Research 54: 517-520

12. Spickett A M, Fivaz B H 1992 A survey of cattle tick control practices in the Eastern Cape Province of South Africa. Onderstepoort Journal of Veterinary Research 59: 203210

13. Steyn G J 1988 A farming systems study of two rural areas in the Peddie district of Ciskei. DSc dissertation, University of Fort Hare, Alice 